\title{
ON RYSZARD SYSKI
}

\author{
J.W. COHEN \\ CWI, P.O. Box 94079 \\ $1090 \mathrm{~GB}$, Amsterdam \\ The Netherlands
}

(Received March, 1997; Revised September, 1997)

This is a brief account on Ryszard Syski's scientific contributions and his collaboration with the author.

Key word: Biography.

AMS subject classifications: 01-00, 01-02.

In June 1955, I received a letter from Harrow, England. It was a reaction to my contribution for the first ITC congress in Copenhagen 1955. Papers for this meeting had been sent to the participants several weeks before the sessions. The letter commenting on my paper about some priority models was signed by Ryszard Syski. A few weeks beforehand I had read a paper, also for the ITC meeting, authored by Syski. That paper impressed me. It was a clear and beautiful exposition of the analysis of basic queueing models then used in telephone traffic engineering; I looked forward to meeting its author. We met in Copenhagen and that encounter was the start of a lasting and most rewarding friendship. At the Copenhagen congress, a committee was nominated for listing all papers in the existing literature on teletraffic studies; Ryszard and I, together with Arne Jensen, were the members. In 1956, the three of us met again in Paris to discuss what we had done and examine the form of the ultimate publication of the list. In our leisure hours we enjoyed the city. We had an outdoor dinner service at a beautiful restaurant in Montmartre. The menu had an exotic choice: frogs' legs. Ryszard and Arne went for it; presumably, I was more hungry. Indeed, this main course was like an error term in a Taylor series: negligibly small! While Arne had to leave Paris, Ryszard and I stayed for another two days. It was a wonderful springtime in Paris; sitting on the stairs of the Sacre Coeur, we discussed our business. Of course we visited the Mona Lisa and the Blue Bell Girls show. At the 1958 ITC meeting, the literature list was handed out to the participants; its composition had been mainly Ryszard's work.

In 1960, Ryszard's book on congestion theory appeared. It included a motivating introduction by Sir Thomas Eades who was a chairman of the Automatic Telephone and Electric Company and Ryszard's employer. Sir Thomas emphasized the significance of teletraffic research for telephone engineering and, apparently, the administration during that time authorized to use some budget on directly fostering theoretical studies in engineering disciplines. 
The book, reprinted in 1986, was a landmark in the development of the teletraffic discipline. It discusses completely the theory since its start around 1900 . Written in a clear and effective style, it provided the engineer with the basic ideas of stochastic processes (hardly taught in engineering courses at that time), in particular, Markov chains. In my personal records I keep the letter Ryszard wrote to me in 1955.

Ryszard has published several books and many papers. He is an enthusiastic teacher. Pollaczek's approach of the GI/G/1-queueing model is one of his favorite subjects. Ryszard took great care to elucidate the work of Pollaczek; they were close friends. Ryszard was influential as an author and teacher; he has also strongly contributed to applied probability in his involvement in several eloquent initiatives.

In the late sixties, some applied probabilists felt the need for international meetings on engineering applications of probability. Ryszard was one of them. The first "Conference on Stochastic Processes and their Applications" was held in Rochester, 1971, organized by Julian Keilson. It became the first one of the yearly series of meetings, later under the auspices of the Bernoulli Society. Ryszard has also been one of the initiators of the founding of a journal with the same theme. After many negotiations, the journal, Stochastic Processes and Their Applications, appeared in 1973. Ryszard was on the first board of editors. It became a sound journal. Unfortunately, after several years it lost its flavor of engineering applications.

In the past forty-two years I have met Ryszard frequently, we have visited each other's universities many times, we have edited conference proceedings together, we have served on many committees together, and we have enjoyed each other's company on numerous outings and at several private meetings. Hardly a year has passed by without an encounter. It has always been a great pleasure to work with him. He is a fine friend, who is always ready to talk, listen, and help.

He has been a member of general Anders' Second Corps. After the Second World War ended, he chose to live as an expatriate. Ryszard missed his homeland Poland and the contact with relatives out there very much. He has dreamed of the time he could return for a visit, which he has finally been able to thirty-five years after the war.

Ryszard did not look forward to his retirement, but surely he will remain the same fine person for all of his numerous friends. I wish him well. 


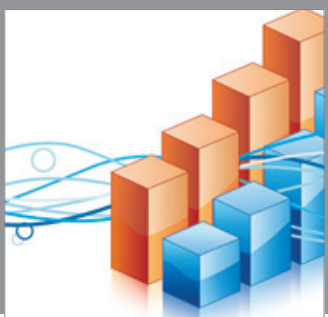

Advances in

Operations Research

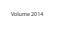

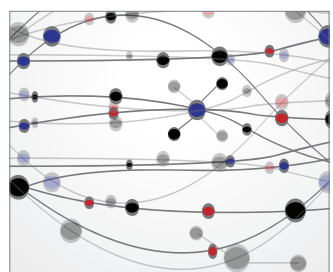

\section{The Scientific} World Journal
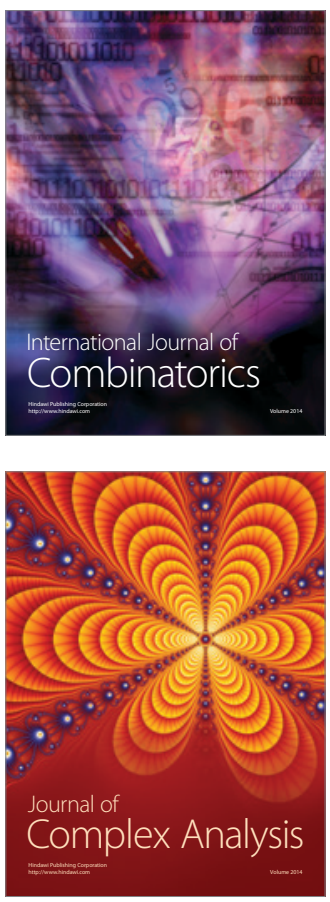

International Journal of

Mathematics and

Mathematical

Sciences
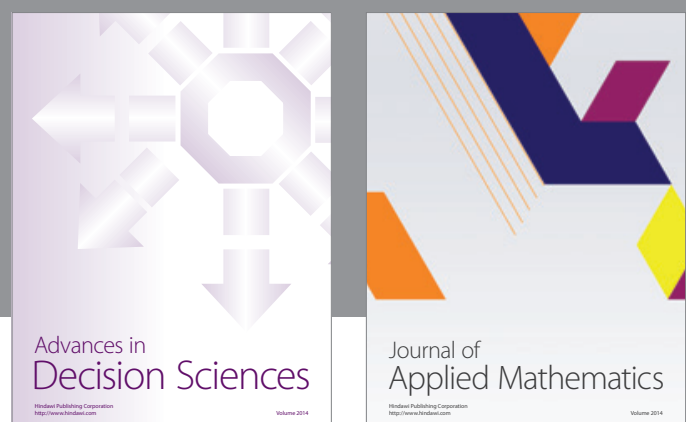

Journal of

Applied Mathematics
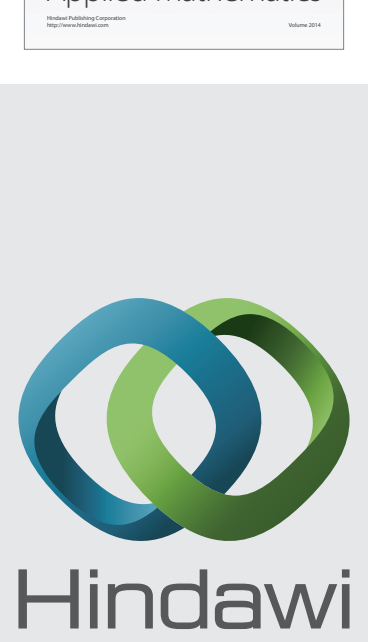

Submit your manuscripts at http://www.hindawi.com
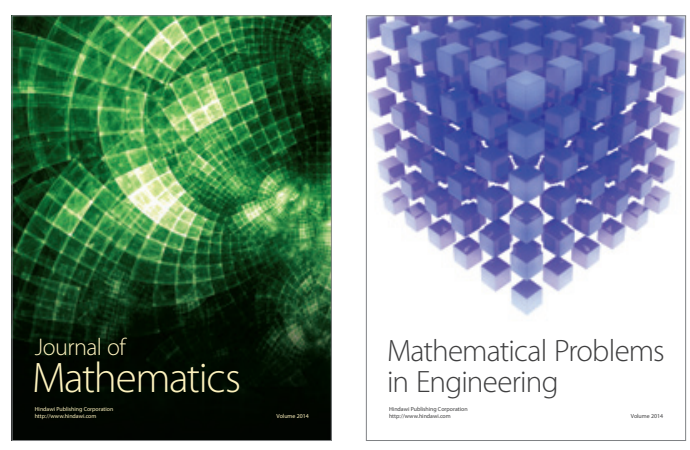

Mathematical Problems in Engineering
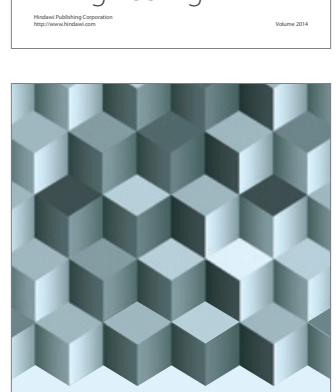

Journal of

Function Spaces
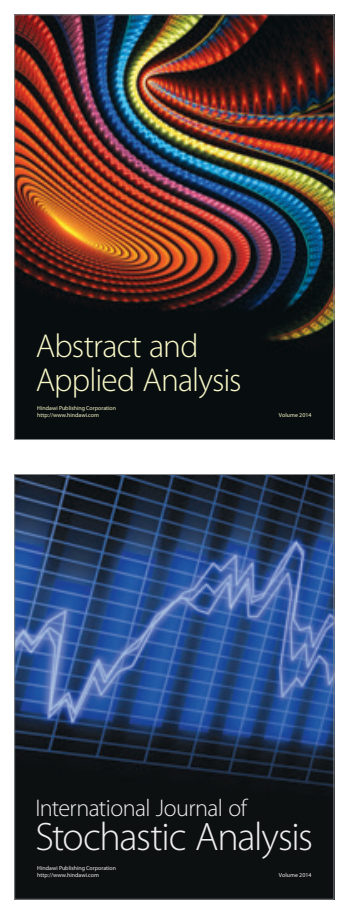

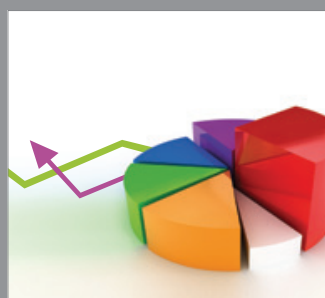

ournal of

Probability and Statistics

Promensencen
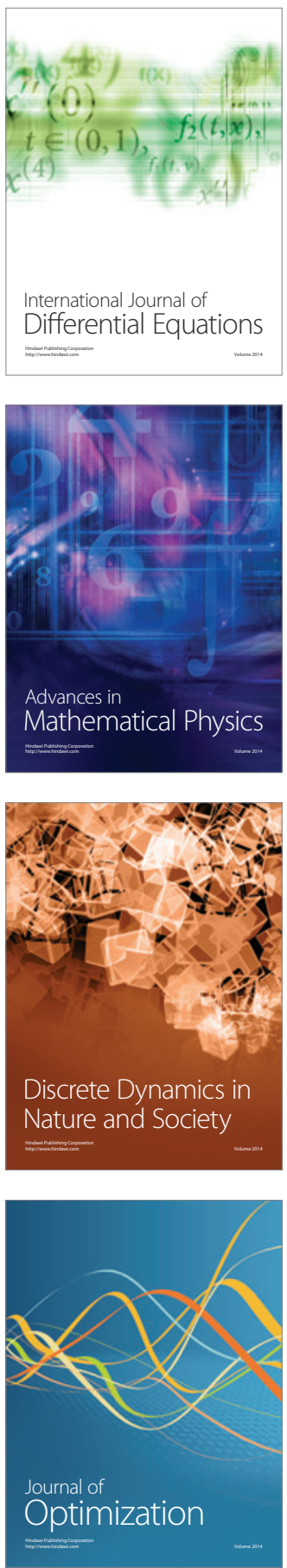